\title{
Global Prevalence of Double Benioff Zones
}

\section{Michael R. Brudzinski, ${ }^{1 *}$ Clifford H. Thurber, ${ }^{2}$ Bradley R. Hacker, ${ }^{3}$ E. Robert Engdahl ${ }^{4}$}

Double Benioff zones provide opportunities for insight into seismogenesis because the underlying mechanism must explain two layers of deep earthquakes and the separation between them. We characterize layer separation inside subducting plates with a coordinate rotation to calculate the slab-normal distribution of earthquakes. Benchmark tests on well-established examples confirm that layer separation is accurately quantified with global seismicity catalogs alone. Global analysis reveals double Benioff zones in 30 segments, including all 16 subduction zones investigated, with varying subducting plate ages and stress orientations, which implies that they are inherent in subducting plates. Layer separation increases with age and is more consistent with dehydration of antigorite than chlorite.

$\mathrm{D}$ espite the passage of nearly 30 years since the discovery of double Benioff zones (DBZs) (1), the nature of these parallel planes of seismicity in a subducting plate remains enigmatic (2-5). Benioff zones represent internal deformation of actively sinking lithosphere as inclined zones of seismicity connecting shallow earthquakes near the trench with earthquakes deep in the mantle. The mechanism for any seismicity below $\sim 70-\mathrm{km}$ depth is a matter of ongoing debate because of the need to overcome high confining pressure that would otherwise prohibit the sudden release of strain as earthquakes [e.g., (6)]. The existence of DBZs presents an important opportunity for gaining insight into earthquakes at intermediate depths of 70 to $300 \mathrm{~km}$, because a hypothesis for such seismogenesis must explain the presence of the two layers and the separation between them. In general terms, earthquakes require two conditions: the presence of sufficient deviatoric stress to generate shear deformation and an adequate mechanism to store and release strain in a seismogenic way. Proposed mechanisms for triggering intermediate-depth seismogenesis that may account for DBZs center around dehydration of hydrothermally altered oceanic lithosphere, with a variety of hydrated rocks being suggested as contributors (e. g., serpentine, chlorite, and gabbro) $(5,7-13)$. Likewise, several mechanisms have been proposed to explain the stress conditions in DBZs, including unbending of the slab [e.g., $(14,15)]$, thermoelastic stress [e.g., (16)], and sagging of the plate [e.g., (17)]. An open question that would provide a key constraint on models for seismogenesis is: Are DBZs common in subduction zones globally as a result of a ubiquitous mechanism, or are they rare because of special

${ }^{1}$ Geology Department, Miami University, Oxford, OH 45056, USA. ${ }^{2}$ Department of Geology and Geophysics, University of Wisconsin, Madison, WI 53706, USA. ${ }^{3}$ Department of Earth Science, University of California, Santa Barbara, CA 93106, USA. ${ }^{4}$ Department of Physics, University of Colorado, Boulder, CO 80309, USA.

*To whom correspondence should be addressed. E-mail: brudzimr@muohio.edu that DBZs are globally prevalent. conditions present in only a few situations? This study provides a preliminary answer to this question: DBZs are relatively widespread.

DBZs have been most successfully characterized in regions where local seismic networks provide adequate coverage to yield relatively high-precision earthquake hypocenters (18-23). We can use such locally "calibrated" DBZs to test the ability of global seismicity catalogs to identify the presence of DBZs and estimate the layer separation. Despite increased location scatter in global catalogs compared with localnetwork catalogs, a benchmark test described below indicates that global catalogs are sufficient for characterizing DBZs. In this study, we investigated (i) whether DBZs are prevalent globally and (ii) potential relationships between DBZ layer separation and subductingplate properties, with special attention to thermal parameters (Fig. 1). The overall prevalence and regularity of DBZs on a global basis will characterize the conditions at depth, both seismic and petrologic, that reveal how a plate evolves after subduction.

We have developed a straightforward method for determining the separation between layers of a DBZ that can also assess the existence of a DBZ. This technique determines the distribution of events in the slab-normal direction for a given slab segment such that seismic layers appear as peaks in earthquake histograms. We use the dip test to establish whether the distribution is multimodal (24); if it is, we calculate the separation between modes and the associated uncertainty using a multiple Gaussian fit (25). Further details on data and analysis are in the Supporting Online Material.

To evaluate the performance of our method for determining DBZ separation with the slabnormal distribution, we applied the technique to what is arguably the best-characterized DBZnortheastern Japan - using hypocenters relocated with the advanced double-difference tomography method and local network data (19). In this case, DBZ separation was easily seen before coordinate rotation due to high-precision event locations (Fig. 2A, top panel), and it has been established to be $\sim 30 \mathrm{~km}(1,19)$. After rotation of the events into down-dip and slab-normal directions (Fig. $2 \mathrm{~A}$, bottom), we found that the distribution is bimodal at $>99.99 \%$ confidence level $(P<$ $0.0001)$ and that the peak-to-peak separation is $31 \mathrm{~km}$.

Having established that the technique can reproduce a DBZ spacing with precisely located events, we compared results for northeastern Japan using the global hypocentral catalogs of Engdahl et al. (EHB) (26, 27, and subsequent updates) and the Preliminary Determination of

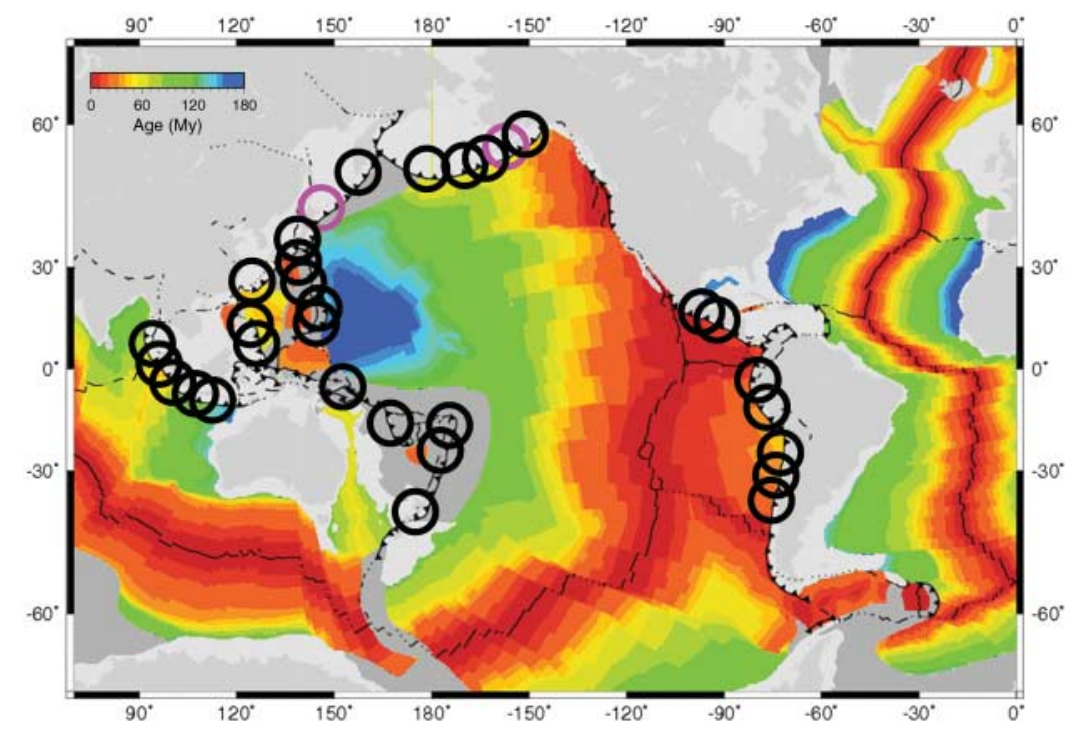

Fig. 1. Subduction-zone segments analyzed, with color scale illustrating seafloor age (28) before being consumed at trenches (barbed lines). Black circles indicate areas with a multimodal distribution of events in the slab-normal direction (pink circles indicate cases with confidence $<95 \%$ ), demonstrating 
Fig. 2. Analysis of DBZ separation using slabnormal distributions. (A) Results for northeastern Japan using relocated, local-network hypocenters (19). Top panel shows events (crosses) in typical crosssection view (gray areas not analyzed), and bottom panel shows events after rotation into down-dip and slab-normal locations. This provides the benchmark for comparison with results using global hypocentral catalogs of (B) EHB $(26,27)$ and (C) PDE. Similar estimates of DBZ separation among the three data sets at several other subduction zones confirm that global catalogs are sufficient to characterize DBZs. (D) Histograms showing slab-normal distribution of EHB events for all segments analyzed, sorted by subducting plate age. DBZ separation is estimated by multiple
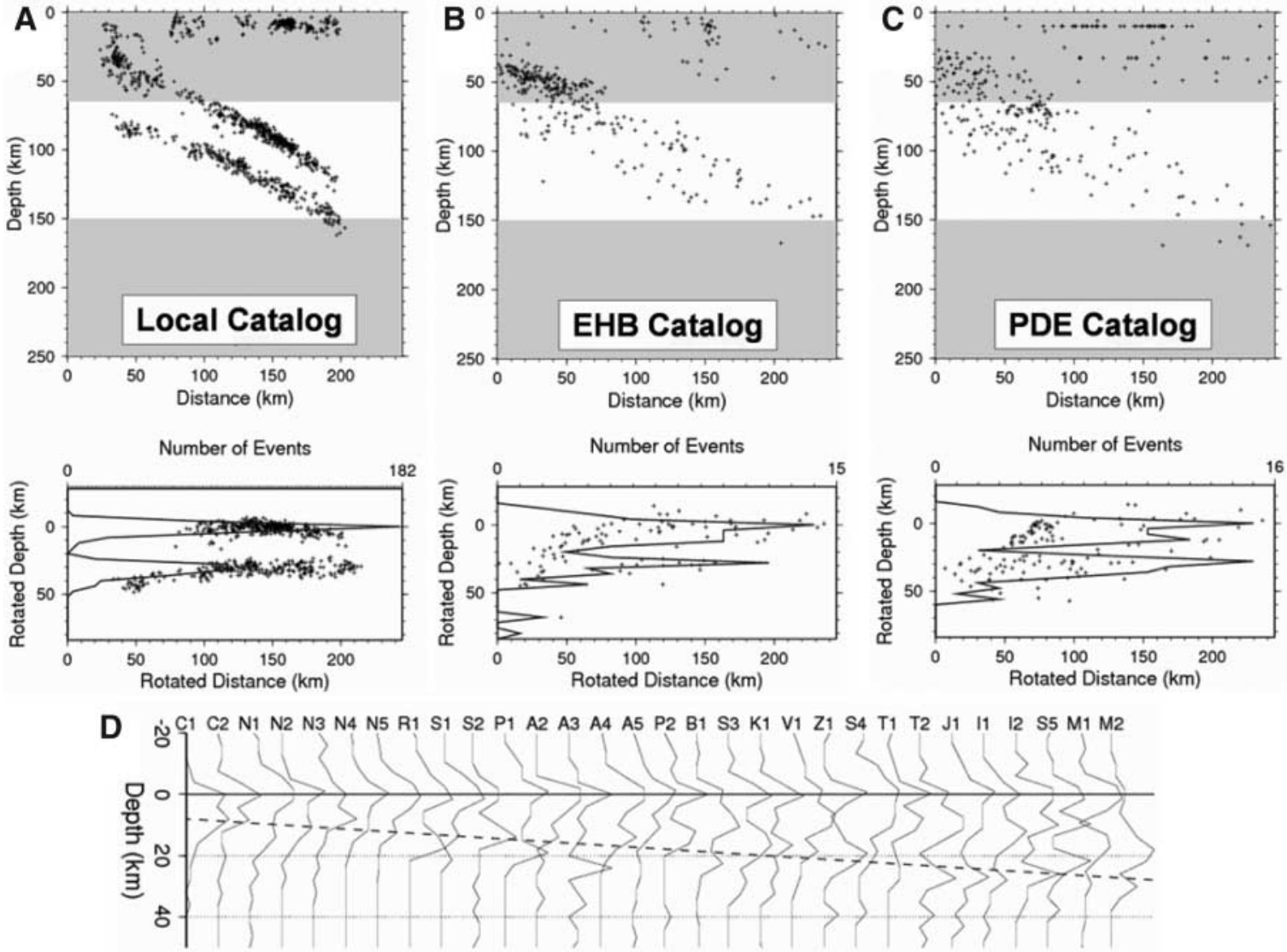

Gaussian fits shown in

green, and dashed linear best fit highlights a significant increase with age.

Epicenters (PDE). The catalogs are constructed only from hypocenters determined using globally reported arrival times and do not include hypocenter solutions from dense local networks. In these cases, the DBZ separation is more difficult to see in a typical cross-sectional view because of the increased scatter in event location and depth, presumably due to the increased effects of subduction zone lateral heterogeneity on global arrival-time data combined with arrival-time pick inaccuracy (Fig. 2, B and C, top). Nevertheless, the slab-normal distribution after coordinate rotation shows two prominent peaks (Fig. 2, B and C, bottom), the dip test for multimodality is easily satisfied $(P<0.01)$, and the separations between the Gaussian peak fits are $30 \mathrm{~km}$ for EHB and $29 \mathrm{~km}$ for PDE.

Comparing the EHB catalog and other available local network locations, we found excellent agreement for the DBZ separation $(18,20,21,23)$. For example, in the case of New Zealand (22), we determined the slabnormal distribution of EHB and local catalog data, finding DBZ separations of $21 \mathrm{~km}$ for each. With the successful benchmark tests in hand, our method allows a new global investigation of DBZ prevalence and patterns in the DBZ separation. We investigated 16 different subduction zones (Alaska, Aleutians, Central Amer-

Fig. 3. DBZ separation versus subducting plate age for each segment analyzed, including 1-SD uncertainties from Gaussian fits. Predictions of DBZ separation due to the lower zone resulting from ultimate dehydration of antigorite (blue) and chlorite (green) are shown based on Hacker et al. (9). Antigorite dehydration is consistent with all observed DBZ separations, whereas chlorite dehydration might explain only a few cases. Separations are not correlated with stress orientations, shown as triangles for

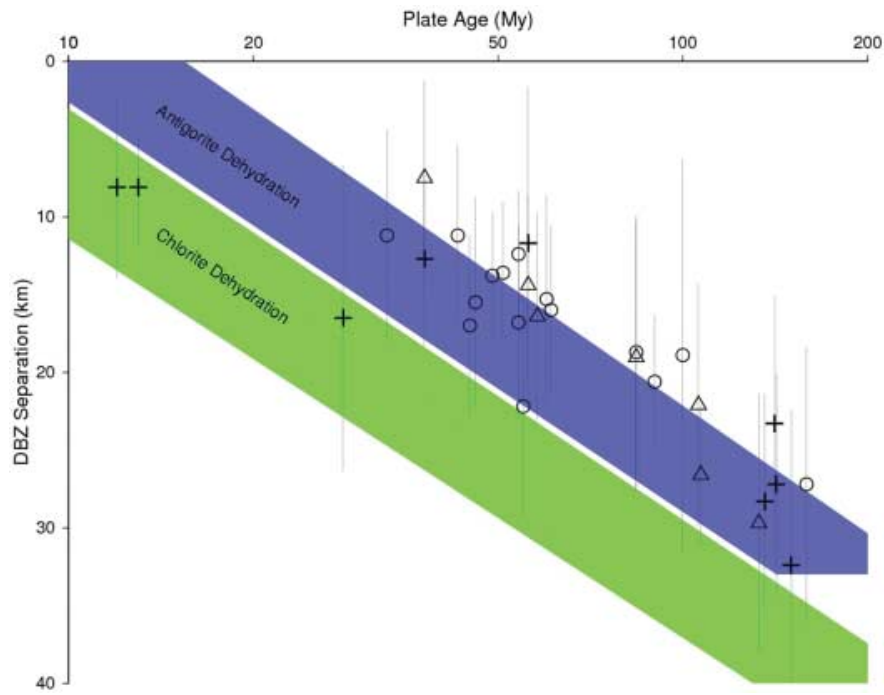

typical down-dip compression overlying down-dip extension, circles for a different pattern, and crosses when the pattern is unknown.

ica, Kurile-Kamchatka, Izu-Bonin, Japan, Mariana, Nazca, New Britain, New Hebrides, New Zealand, Philippines, Ryukyu, Sumatra, Sunda, and Tonga) that account for a range of subducting plate ages [ $\sim 10$ to 160 million years (My)] (Fig. 1) (28) and slab dips $\left(\sim 0\right.$ to $\left.70^{\circ}\right)$ (table $\left.\mathrm{S} 1\right)$.
After constructing histograms for the slabnormal distribution of events in the EHB catalog for each region (Fig. 2D), we found 30 different segments that have a bimodal or trimodal distribution that fulfills the dip test for multimodality (table S1). When the results for slab-normal dis- 
tribution of events are sorted by age of subducting plate (Fig. 2D), the DBZ separation reveals a significant increase with plate age, from $\sim 8 \mathrm{~km}$ for a $\sim 12$-My-old slab up to $\sim 30 \mathrm{~km}$ for a $\sim 160$-My-old slab. A linear estimate for the DBZ separation versus age relationship is $\sim 0.14 \mathrm{~km} / \mathrm{My}$, but the data can also be fit with a log-linear relationship.

Every subduction zone studied has at least one segment with a DBZ (Fig. 1), suggesting that DBZs are ubiquitous features. However, our method was not able to identify a DBZ in every section of every subduction zone. This is mainly due to difficulties constructing cross sections in areas with less seismicity, where wider cross sections raise problems with trench curvature or changes in slab dip. Two clear cross sections that did not meet the dip test for multimodality in Kurile-Kamchatka and Eastern Aleutians have been reported as transitions from a DBZ to a single Benioff zone, interpreted as situations where stresses are reduced $(4,29)$. Moving from northeast to southwest in Kurile-Kamchatka, the decreasing compressive stress transmitted from greater depth is thought to control changes from single compressive zone to DBZ to single extensive zone.

Further evidence for the variable stress regime in DBZs globally can be seen in a survey of reported focal mechanisms (table S1), with several DBZs showing patterns different from the conventional compressive upper layer and extensive lower layer (1) (Fig. 3). This places new constraints on models for the source of stress in DBZs, which leads us to question the viability of each of the proposed models (thermoelastic, slab unbending, and sagging plate), which may have difficulty generating sufficient levels of stress for the wide range of slab temperatures, configurations, and focal mechanisms. The systematic variation in layer separation with plate age despite variations in stress orientations also suggests that the trend in layer separations is not controlled by intraplate stresses. Instead, the discovery of DBZs over a wide range of ages and focal mechanisms indicates that the conditions for seismogenesis can be met in two separate layers within plates at intermediate depths regardless of the slab thermal state and stress orientation. Thus, the triggering mechanism does not result from an unusual set of circumstances, but must be common in subduction zones.

The triggering mechanism for DBZs has typically been interpreted as due to the thermalpetrological evolution of the subducting plate [e.g., (9)]. One proposed mechanism for intermediatedepth seismogenesis that may account for DBZs is the breakdown of hydrous phases to produce a free fluid - and therefore zero effective pressureallowing brittle faulting (e.g., 7, 13, 30, 31) (32). A variety of hydrous minerals have been suggested as contributors, with metamorphosed basalt near the top of the plate being the pri- mary candidate for the upper zone of seismicity $(5,9-11,19)$. Recently, the upper zone beneath northern Japan has been proposed to consist of two thin layers of seismicity with different focal mechanisms separated by a few kilometers (33). Although the global database used here is likely insufficient to see such a triple seismic zone, there are a few segments in this study (i.e., J1, T1, and T2) where a trimodal solution with a small separation between peaks in the upper layer provides a better fit than a bimodal solution.

Petrologic candidates that might explain the lower zone of DBZ seismicity as the result of dehydration include antigorite (12) and chlorite (9) in hydrous peridotite (34). The chloritedehydration reaction occurs at higher temperatures of 700 to $800^{\circ} \mathrm{C}$ (deeper within the plate), so the dipping seismic zone associated with this reaction would occur up to $10 \mathrm{~km}$ below that associated with antigorite dehydration at 600 to $650^{\circ} \mathrm{C}$, generating a larger DBZ separation (9). Given this difference between the two dehydration reactions, we compared the results for DBZ separation versus subducting plate age found in this study with separations predicted for the dehydration of antigorite and chlorite based on the thermal-petrological models of Hacker et al. (9) (Fig. 3). Antigorite dehydration is consistent with all the observed DBZ separations, whereas chlorite dehydration can explain only a few cases. Given the variation of stress orientations in DBZs of our study areas, the lack of larger separations that would indicate chlorite dehydration is not due to stress limitations. This implies that the lower zone of earthquakes at intermediate depths is most likely associated with fluid released from antigorite breakdown. Given that serpentinized peridotite can store several times more water than chlorite-bearing peridotite (9), the amount of fluid released may be a key factor in generating earthquakes, which could be used to evaluate the seismogenic potential of other dehydration reactions [or perhaps phase changes that result in fluidlike material (35)].

Regardless of whether our inference about antigorite breakdown is correct, our finding that DBZs are found in all subduction zones worldwide requires that any triggering mechanism to explain DBZ seismicity (and hence intermediate-depth earthquakes in general) must be present in all subduction zones regardless of plate age, convergence rate, or stress orientation.

\section{References and Notes}

1. A. Hasegawa, N. Umino, A. Takagi, Geophys. J. R. Astron. Soc. 54, 281 (1978).

2. G. A. Abers, in Subduction: Top to Bottom, G. E. Behout et al., Eds. (American Geophysical Union Geophysical Monograph, 1996), vol. 96, pp. 223-228.

3. K. Fujita, H. Kanamori, Geophys. J. R. Astron. Soc. 66, 131 (1981).

4. H. Kao, W.-P. Chen, J. Geophys. Res. 99, 6913 (1994).

5. T. Yamasaki, T. Seno, J. Geophys. Res. 108

10.1029/2002JB001918 (2003)
6. C. H. Scholz, Mechanics of Earthquakes and Faulting (Cambridge Univ. Press, Cambridge, 1990).

7. H. Jung, H. W. Green, L. F. Dobrzhinetskaya, Nature 428, 545 (2004)

8. B. R. Hacker, G. A. Abers, S. M. Peacock, J. Geophys. Res. 108, 2029 (2003)

9. B. R. Hacker, S. M. Peacock, G. A. Abers, S. D. Holloway, J. Geophys. Res. 108, 2030 (2003).

10. S. H. Kirby, E. R. Engdahl, R. P. Denlinger, in Subduction Top to Bottom (American Geophysical Union, Washington, DC, 1996), vol. 96, pp. 195-214.

11. D. M. Kerrick, J. A. D. Connolly, Earth Planet. Sci. Lett. 189, 19 (2001)

12. S. M. Peacock, Geology 29, 299 (2001).

13. D. P. Dobson, P. G. Meredith, S. A. Boon, Science 298, 1407 (2002)

14. B. L. Isacks, M. Barazangi, Eds., Geometry of Benioff Zones: Lateral Segmentation and Downwards Bending of the Subducted Lithosphere, vol. 1 (American Geophysical Union, Washington, DC, 1977), pp. 99-114.

15. E. R. Engdahl, C. H. Scholz, Geophys. Res. Lett. 4, 473 (1977).

16. H. Hamaguchi, K. Goto, Z. Suzuki, J. Phys. Earth 31, 329 (1983).

17. N. H. Sleep, J. Geophys. Res. 84, 4565 (1979)

18. G. A. Abers, Geophys. Res. Lett. 19, 2019 (1992).

19. H. J. Zhang et al., Geology 32, 361 (2004).

20. N. A. Ratchkovsky, ]. Pujol, N. N. Biswas, Tectonophysics 281, 163 (1997).

21. A. Rietbrock, F. Waldhauser, Geophys. Res. Lett. 31, L10608, 10.1029/2004GL019610 (2004).

22. W. X. Du, C. H. Thurber, M. Reyners, D. Eberhart-Phillips, H. J. Zhang, Geophys. J. Int. 158, 1088 (2004).

23. H. Kao, R. J. Rau, J. Geophys. Res. 104, 1015 (1999).

24. J. A. Hartigan, P. M. Hartigan, Ann. Stat. 13, 70 (1985)

25. W. Menke, Geophysical Data Analysis: Discrete Inverse Theory (Academic Press, New York, ed. 2, 1989), pp. 289.

26. E. R. Engdahl, R. D. van der Hilst, R. P. Buland, Bull. Seismol. Soc. Am. 88, 722 (1998).

27. E. R. Engdahl, A. Villasenor, in International Handbook of Earthquake and Engineering Seismology, Part A, W. H. K. Lee, H. Kanamori, P. C. Jennings, C. Kisslinger, Eds. (Academic Press, Amsterdam, 2002), chap. 41, pp. $665-690$

28. R. D. Müller, W. R. Roest, J.-Y. Royer, L. M. Gahagan, J. G. Sclater, J. Geophys. Res. 102, 3211 (1997).

29. K. W. Hudnut, ]. ]. Taber, Geophys. Res. Lett. 14, 143 (1987)

30. C. B. Raleigh, M. S. Paterson, J. Geophys. Res. 70, 3965 (1965).

31. S. Kirby, Rev. Geophys. 33, 287 (1995).

32. "Dehydration embrittlement" is a special case of this process in which embrittlement occurs at the site of dehydration and immediately at the time of dehydration.

33. T. Igarashi, T. Matsuzawa, N. Umino, A. Hasegawa, J. Geophys. Res. 106, 2177 (2001)

34. Hydration of the slab mantle may occur by outer-rise normal faulting (11) or by upward fluid flow within a dipping slab (8).

35. H. W. Green II, Y. Zhou, Tectonophysics 256, 39 (1996).

36. This material is based on work supported by the National Science Foundation under grants EAR-0337495 (U.W.), EAR-0542253 (M.U.), and EAR-0215641 (U.C.S.B.). We thank M. Hughes for statistical guidance and H. DeShon, S. Kirby, and H. Zhang for helpful discussions.

Supporting Online Material

www.sciencemag.org/cgi/content/full/316/5830/1472/DC1 Methods

SOM Text

Table S1

References

22 December 2006; accepted 24 April 2007 10.1126/science.1139204 
ple, motions of an $\alpha$-helix might cause similar changes in the electrical fields acting on several pigments bound to that helix.

Electronic coherence could facititate energy migration by allowing excitations to be sensed simultaneously at multiple sites within the protein. These ideas remain to be explored by detailed molecular-dynamics simulations and quantum calculations. It seems clear, however, that a complete description of energy migration in photosynthetic complexes will have to include electroniceonerence.

Recent work by Woodbury and co-workers (10) atdresses how motions of the reaction center protein affect the rate of electron transfer from the bacteriochlorophyll dimer to the initial electron acceptors. Their results suggest that the energies of the electron-transfer states may be more strongly coupled to protein motions than are the shorter-lived excited states probed in the photon-eetho experiments by Fleming and co-workers $(1,9)$.

\section{References}

1. H. Lee, Y.-C. Cheng, G. R. Fleming, Science 316, 1462 (2007).

2. R. J. Stanley, B. King, S. G. Boxer, J. Phys. Chem. 100, 12052 (1996).

3. M. H. Vos, ]. Breton, ]. L. Martin, J. Phys. Chem. B 101 9820 (1997).
4. B. A. King, T. B. McAnaney, A. deWinter, S. G. Boxer J. Phys. Chem. B 104, 8895 (2000).

5. S. Mukamel, Principles of Nonlimear Optical Spectroscopy (Oxfot Univ. Press, Oxford, 1995).

6. W. W. Paron, Modern Optical Spectroscopy with

Examples from Biophysics and Biochemistry (Springer, Berlin, 2006).

7. M. H. Vos, M. R. Jones, C. N. Hunter, ]. Breton, ].-L. Martin, Proc. Natl. Acad. Sci. U.S.A. 91, 12701 (1994).

8. M. H. Vos, F. Rappaport, ].-H. Lambry, J. Breton, ].-L. Martin, Nature 363, 320 (1993).

9. G. S. Engel et al., Nature 446, 782 (2007).

10. A.Wang et al., Science 316, 747 (2007).

11. U. Ermler, G. Fritzsch, S. K. Buchanan, H. Michel, Structure 2, 925 (1994).

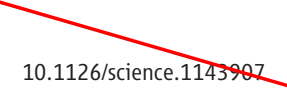

\section{GEOPHYSICS}

\section{Listening to the Crackle of Subducting Oceanic Plates}

Double zones of seismic activity now appear to be a general feature of tectonic plates pushed deep into Earth, providing new clues to the sources of deep earthquakes.

Andreas Rietbrock

A reas called subduction zones occur under the ocean where one section of Earth's crust (the lithosphere) collides with another and descends into the mantle (see the figure). Although these zones are of substantial scientific interest, they also have great social and economic importance. Most of the world's disastrous earthquakes and volcanoes take place at subduction zones, as well as geological processes that generate many of the ore deposits on Earth.

We can map the path of the descending lithospheres by measuring the abundant seismic activity in the subduction zone. Since it was first observed in the early 1930s, however, the precise nature and cause of this seismicity has been debated. On page 1472, Brudzinski et al. report a major step forward in our understanding of the geophysical and geochemical processes at work in these seismic regions (1).

The deep layers of seismic activity in subducting regions are called Wadati-Benioff zones (WBZs) and can be found as deep as $700 \mathrm{~km}$. Originally, WBZs were believed to be single layers of seismic activity, but they have turned out to be more complex. The first convincing observation of a double WBZ beneath northern Honshu, Japan, was made by Hasegawa et al. (2), and they reported a separation distance between the two layers of about 30 to $40 \mathrm{~km}$. Since then, the geoscience community has been

The author is in the Department of Earth and Ocean Sciences, Liverpool University, Liverpool L69 3GP, UK. E-mail: A.Rietbrock@liverpool.ac.uk puzzled by the relative rarity of double WBZs.

Recently, as a result of a huge increase in seismological data collected and the availability of new data-processing tools, hints of double WBZs with much smaller separation distances $(<10 \mathrm{~km})$ have been found in many different subduction zones (3). Brudzinski et al. have taken these observations further and propose that double layering of seismicity is an inherent feature of WBZs in the depth range between 50 and $300 \mathrm{~km}$ (which they refer to as double Benioff zones, or DBZs).

The origin of WBZ seismicity has been controversial for several reasons. Brittle failure or, more precisely, sudden slip along a preexisting fault or plate interface is the cause for most of the earthquakes in Earth's crust ( $<50 \mathrm{~km}$ depth). However, due to the high temperature and pressure at the depth level of WBZ seismicity the material will instead undergo ductile deformation, which inhibits earthquake faulting. Therefore, different processes are necessary for the generation of WBZ seismicity.

A commonly accepted model for this deeper activity is dehydration embrittlement, in which fluids released by hydrous minerals of the crust and mantle of the slab can lead to high pore pressures, reduce the effective stress on preexisting faults, and hence promote the occurrence of earthquakes (4). In the upper layer of seismicity, researchers believe that a mineral transformation from basalt to eclogite in the oceanic crust is the main reaction promoting earthquakes and causing an increase of seismicity in this depth range. As yet, there is no such consensus about which of the numerous possible hydrous minerals might explain the lower band of seismicity in double WBZs.

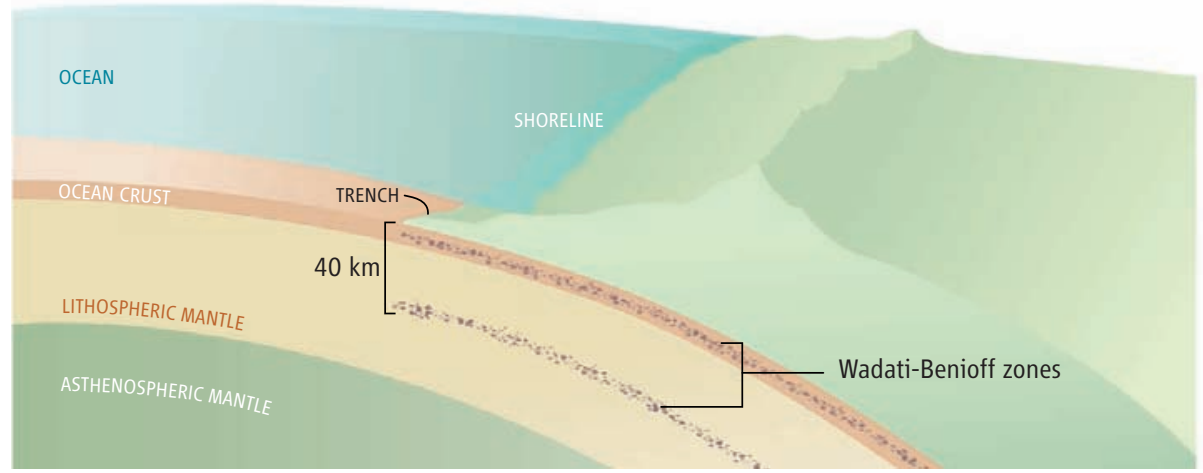

Double seismicity. At subduction zones, one tectonic plate descends under another. Earthquakes occur along surfaces called Wadati-Benioff zones (WBZs) to depths of more than $700 \mathrm{~km}$. Brudzinski et al. have now found that double WBZs may be a general feature of subduction zones. From these observations, detailed geophysical and geochemical processes inside them can be deduced. 
Brudzinski et al. have now found a direct correlation whereby older oceanic plates show a greater distance between regions of seismicity. They conclude, based on thermalpetrological models developed by Hacker et al. (5), that dehydration of the mineral antigorite is responsible for the seismicity in the lower layer of double WBZs.

Although the detailed geophysical explanation presented by Brudzinski et al. for the double seismic zone might be debatable, they observe that double WBZs are the rule and not the exception during subduction of oceanic lithosphere. This provides an important new constraint for all models developed to explain the occurrence of WBZ seismicity. However, further work on the stress accumulation and dissipation in the lithosphere during subduction is necessary to understand the faulting mechanism causing seismicity in double WBZ or even triple WBZ, as proposed for some regions beneath Japan (6).

Brudzinski et al. show that, as the number of seismological stations and the availability of digital seismic traces increases, the global earthquake catalog will become accurate enough to delineate the fine structure of seismicity (on the order of a few kilometers) on a global scale. This accuracy will increase in the near future as a result of large seismological observation initiatives like EarthScope in the United States or the NERIES program
(Network of Research Infrastructures for European Seismology) in Europe, which will make more high-quality digital data readily available for seismologists worldwide.

\section{References}

1. M. R. Brudzinski, C. H. Thurber, B. R. Hacker, E. R. Engdahl, Science 316, 1472 (2007)

2. A. Hasegawa, N. Umino, A. Takagi, Tectonophysics 47, 43 (1978).

3. A. Rietbrock, F. Waldhauser, Geophys. Res. Lett. 31, 10.1029/2004GL019610 (2004)

4. S. Kirby, Rev. Geophys. 33, 287 (1995).

5. B. R. Hacker, G. A. Abers, S. M. Peacock, J. Geophys. Res. 108, 2029 (2003).

6. T. Igarashi, T. Matsuzawa, N. Umino, A. Hasegawa, ]. Geophys. Res. 106, 2177 (2001).

10.1126/science. 1141921

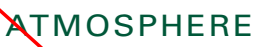

\section{Deglaciation Mysteries}

\section{Ralph F. Keeling}

$\mathrm{B}$ etween 19,000 and 11,000 years ago, the Earth emerged from the last glacial period. During this deglaciation, the carbon dioxide $\left(\mathrm{CO}_{2}\right)$ concentration in the atmosphere rose from 180 to 265 parts per million (ppm). Over the same period, the radiocarbon content of the $\mathrm{CO}_{2}$ fell by $\sim 35 \%$. A simple but unproven explanation for both changes is an increase in the rate at which the ocean's subsurface waters were renewed by exchange with aerated surface waters - a process known as ventilation. A ventilation increase could increase atmospheric $\mathrm{CO}_{2}$ concentration by releasing excess $\mathrm{CO}_{2}$ that had accumulated in subsurface waters by the decomposition of sinking detritus. On page 1456 in this issue, Marchitto et al. (1) bolster the case for such a ventilation increase and offer insight into how the increase may have occurred.

To track changes in past ventilation, most researchers have turned to measurements of the radiocarbon $\left({ }^{14} \mathrm{C}\right)$ content of shells of foraminifera, a ubiquitous narine microorganism. Radiocarbon is produced naturally in the upper atmosphere by cosmic rays and spreads through the ocean as part of the pool

The author is the Scripps Institution of Oceanography, University of California, San Diego, CA 92093, USA E-mail:yeeling@ucsd.edu

Results from a sediment core provide insights into ocean circulation changes during the last deglaciation.

Deep-water ventilation. This cross secth of the Pacific Ocean shows how poorly ventilated water may have been deliveled to intermediate depths during deglaciation, as suggested by Marchitto et Al. (Top) Ventiation of the deep ocean by sinking around Antarctica was partizkty suppressed by a cap formed by sea ice or a layer of low-salinity water. (Botton) This cap was removed duing early deglacial warming, exposing upwelled/eep waters to the atmosphere, Keleasing radiocarbondepleted $\mathrm{CO}_{2}$. The density of the poorly ventilated waters was keduced by freshening and warming With reduced density, the water could spread widely at intermediate depths, displacing waters of similar density.

of dissolved carbon. Because of radioactive decay, waters that are more isolated from the atmosphere (that is, more poorly ventilated) have lower ${ }^{14} \mathrm{C} /{ }^{12} \mathrm{C}$ ratios, as do the shells that grow in these waters. The radiocarbon age of a fossil shell therefore reflects the age of the shell plus the age of the water in which it lived. By subtracting the radiocarbon ages of surface-dwelling (planktonic) and bottomdwelling (benthic) foraminifera, picked from the same layer of a sediment core, it is possible to estimate age difference of surface and deep waters, which is a measure of the deep-water ventilation rate. This technique, applied to numerous sediment cores, has thus far mainly yielded the unremarkable result that the ventilation rate of the glacial ocean was very similar to that of today's ocean, at least down to a depth of $\sim 2800 \mathrm{~m} \mathrm{(2).} \mathrm{Thus,} \mathrm{if} \mathrm{there}$ was a major change in ocean ventilation during deglaciation, this change must have occurred in ocean waters below that depth. However, despite some tantalizing results (3), no general picture has emerged for waters below $2800 \mathrm{~m}$, because of methodological difficulties related to the low sedimentation rates that typically characterize cores from these depths.

Marchitto et al. focus on a sediment core recently hauled up offBaja California from a depth of $700 \mathrm{~m}$, seemingly too shallow for studying deep ventilation. The core contains bands corresponding to a set of millennial climate oscillations first discovered in ice cores from Greenland, allowing absolute dates to be fixed within the core. Using these dates, tha authors correct the ${ }^{14} \mathrm{C} /{ }^{12} \mathrm{C}$ ratios of benthic foraminifera for radioactive decay, thus establishing the original ${ }^{14} \mathrm{C} /{ }^{12} \mathrm{C}$ ratio of the water in which the foraminifera lived. The technique does not require ${ }^{14} \mathrm{C} /{ }^{12} \mathrm{C}$ measurements on planktonic 